Masuma H. Mammadova1, Faig R. Mammadzada ${ }^{2}$

${ }^{1,2}$ Institute of Information Technology of ANAS, Baku, Azerbaijan

1masuma.huseyn@iit.ab.az, ${ }^{2}$ faig.mammadzada@idrak.az

\title{
ANALYSIS TECHNIQUE OF IT-PROFILE EDUCATION AND MATCHING OF SUPPLY AND DEMAND FOR IT SPECIALISTS
}

In this article, the current state of IT-profile education in Azerbaijan is analyzed. The technique of quantitative assessment of IT specialists' demand market that considers the number of IT graduates and mandatory replacement of the specialists outflow from the IT segment is developed. The imbalance in the supply and demand of IT specialists at the national level, in the ICT segment and in other branches of economy is determined.

Keywords: IT-segment, labor market, IT-profile education, quantitative assessment of demand market, IT staff replacement, IT specialists' supply and demand imbalance.

\section{Introduction}

Currently, information technology (IT) directly affects the productivity growth and the pace of economic development in many countries. The feature of the IT sector is that the main resource of the industry is the human - IT professionals, whereas the product is the outcomes of the intellectual activity of the latter. Therefore, the development of IT in any country directly depends on the availability of the essential human resources, which is determined by the quantitative ratio of demand and supply for IT professionals. In this regard, the issues of effective management of the IT labor market and the development of scientifically grounded solutions to ensure the compliance of the IT-profile training system meeting the labor market requirements are of a strategic importance.

In practice, labor market management becomes possible based on the analysis and identification of the real state of the labor market. It is necessary to investigate the IT segment of the labor market in the context of an individual country, using all possible information sources characterizing the main parameters of this object from various aspects. This, in turn, involves the solution of the following tasks:

1) analysis of the current state of the IT-segment of the labor market from the perspective of demand; provision of human resources;

2) analysis of the current state of the IT-profile education market as the main source of IT specialists' demand;

3) joint research of supply and demand in the IT-segment of the labor market and assessment of the level of satisfaction of the demand for IT professionals with the IT-profile education system.

Analysis of the labor market involves the acquisition, systematization, synthesis and evaluation of the available information (formal and informal) on the supply and demand in the labor market of IT professionals. Identification of the state of the labor market is reduced to the determination of the relationship between supply and demand, the type and degree of imbalance in supply and demand using the data acquired through the analysis.

The acquired information will enable to reveal the real ratio of supply and demand for IT specialists in Azerbaijan, to conclude on the degree of balance between the IT-segment of the labor market and IT-profile education, and to develop well-grounded solutions for bringing the system of training IT personnel in line with the requirements of the economy of the country.

There are no universal practical quantitative assessment techniques for supply and demand in the labor market, including in the IT segment. The main reason for this is "binding" the techniques for the investigation of the labor market to the context of the country, which is determined by the development level of the economy, the education system, human resources, the specifics of the information and legal environment. Therefore, if the required information is available, it is necessary to adapt existing approaches and methods for quantitative 
assessment of supply and demand in the labor market. Otherwise, the development of new approaches and techniques is required.

In this paper, we propose a technique for analyzing the IT-profile education and the level of balance between supply and demand for IT professionals in Azerbaijan.

\section{Analysis of the state of IT-profile education in Azerbaijan}

The interaction of the IT segment of the labor market and the IT-profile education market determines the social command for the quality and quantity of the educational services for the training of IT professionals. The peculiarity of the education market, which is one of the most important subsystems of the social sphere, lies in the fact that this field of activity provides the process of formation of human capital through the acquisition and improvement of the quality of knowledge and skills. In order to find out how the rapidly changing needs of the IT professionals' labor market are met by the education market in the context of a particular country, it is necessary, first of all, to analyze the state of the IT education market and reveal the dynamics of the number of IT-profile graduates. The graduates of IT-profile specializations are the main source of supply. Therefore, the information obtained will allow estimating the supply and demand ratio for IT professionals, making conclusion regarding the degree of balance between the IT-segment of the labor market and the IT-profile education system, and developing the valid solutions for bringing the training system of IT-staff in accordance with the requirements of the labor market. The foregoing allows determining the scope, subject matter, and the goal of the study.

The scope of the research is the labor market of IT specialists in Azerbaijan.

The subject matter of the research is an analysis of the current situation in the field of ITprofile education and the identification of the labor market of IT-professionals in Azerbaijan.

The goal of the research is to develop a technique for the analysis of IT-profile education and the copmliance rate of supply and demand for IT-professionals in Azerbaijan. According to the State Statistics Committee (SSC) of Azerbaijan, 54 higher educational institutions are functioning in the country for today (fig.1). The World Bank's study shows that ICT-specialties are trained averagely at 27 universities of the country and, approximately, 2,680 students become graduates annually [1]. This means that half of the universities of the republic train specialists in the field of ICT. However, the data given in this study [1] do not describe the time horizon of the study. However, the indicator of the average number of the annual graduation of IT specialists does not provide tracking the growth dynamics and supply of IT-staff and identifying their distribution of by the IT- specializations. It should also be noted that the official statistics do not ensure data on the total number of admission and graduation of the students in terms of specific IT-professions and specialties, including the group of IT-specializations, and the similar information in the context of individual universities.

Initial data. SSC provides the data on the number of admission to and graduation from higher education institutions in the context of enlarged groups of specialties within the framework of bachelor and master's programs. Taking into account the fact that the main source of potential candidates compensating for the deficit of IT-specialists are representing the natural-scientific and technicaltechnological specialties, based on the statistical data [2], the dynamics of the distribution of the total number of students studying, the total number of students studying in the groups of natural and technical-technological specialties during 2010-2011 / 2015-2016. (Fig. 2). 


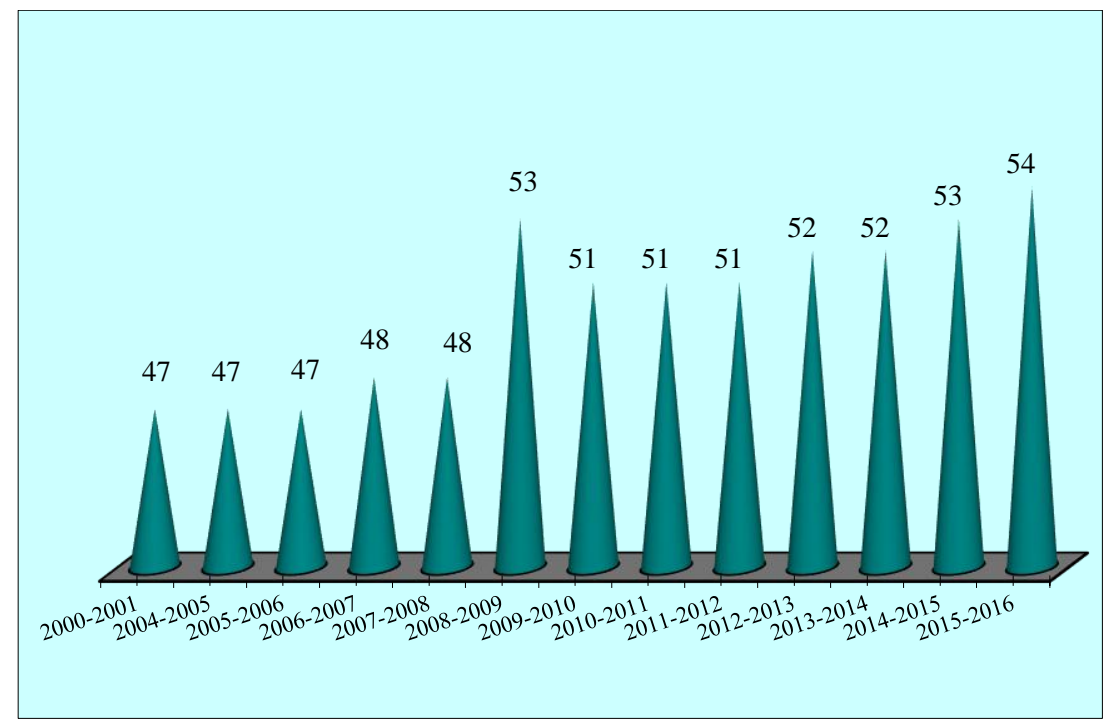

Fig. 1. Dynamics of the number of state and non-state universities of Azerbaijan (at the beginning of the academic year). Source: [2]

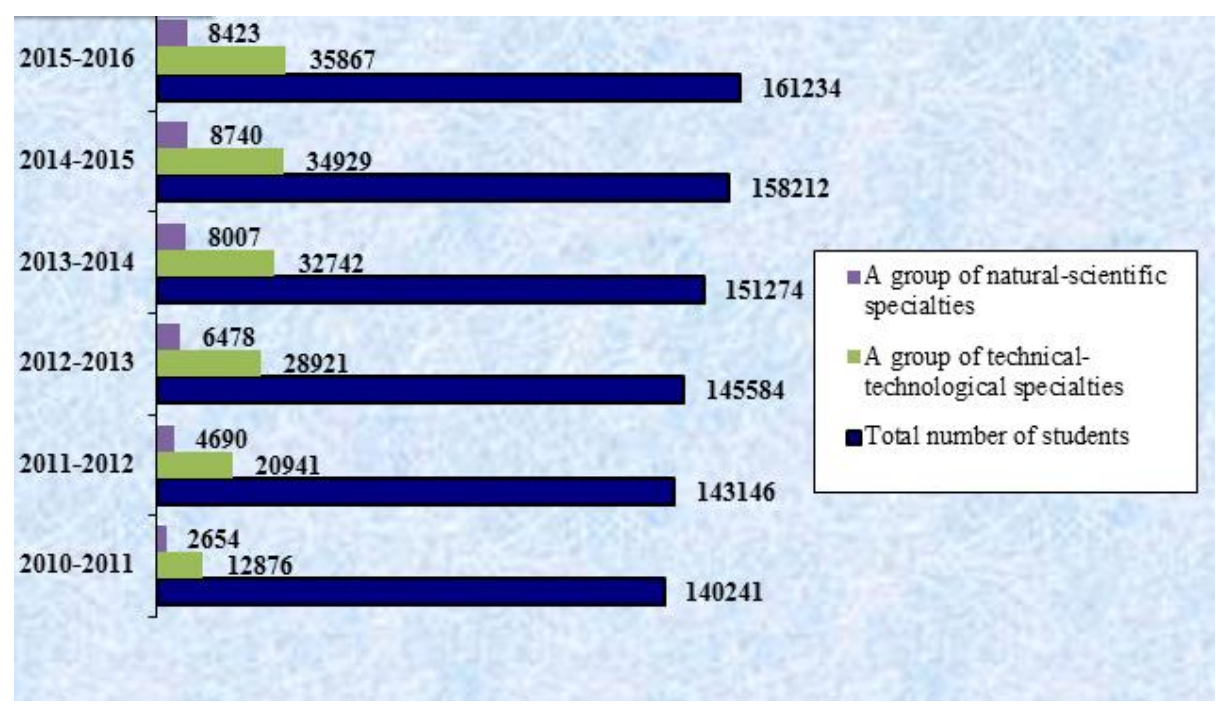

Fig.2. Dynamics of the number of students studying at universities in bachelor's and master's programs. Source: SSC [2]

The State Student Admission Committee (SSAC), upon request, provides the statistical data on the admission of the students to the IT-specialty at all universities of Azerbaijan for the period of 20042005 / 2014-2015. The graphical representation of the students' enrollment dynamics, provided in Fig. 3 , demonstrates the annual increase in the plan for the students' admission to the IT- specialty. Subsequently, in the 2004/2005 academic year, only 965 students were admitted to the IT-specialty, while in the 2014/2015 academic year, this figure reached 2987 people increasing by 3 times within 10 years. 


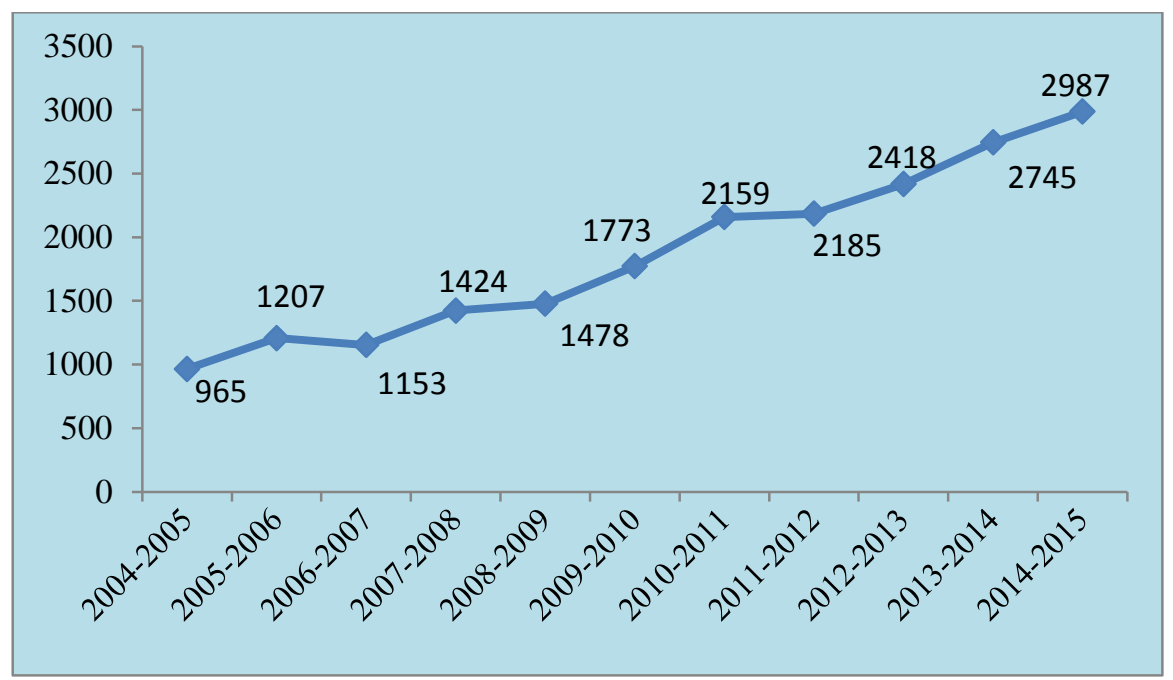

Fig.3. Dynamics of students' admission to IT-specialties. Source: SSAC

However, the lack of statistical data on the graduation of IT-professionals does not enable a direct assessment of the volume of supply of the latter. Further, as the statistical data on the students' admission in the context of groups of specialties (including natural-scientific and technical-technological groups) have been introduced into the category of statistical indicators since 2010, and the students' graduation - since 2013, the horizons for changing these indicators are incomparable with the horizon of the changes in the dynamics of IT-specialties. To ensure the compatibility of the indicators, a joint dynamics of the total number of students enrolled in bachelor's programs and in groups of IT-specialties is Figure 4.

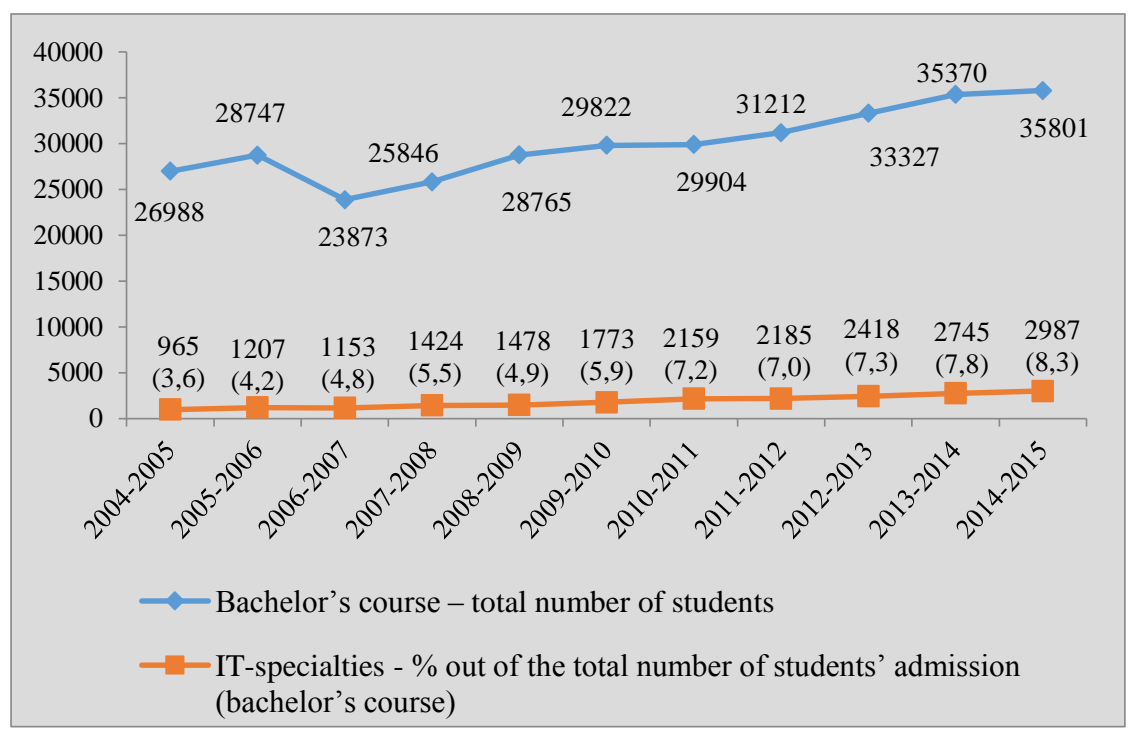

Fig.4. Dynamics of the number of students studying at the universities on the bachelor's programs and the group of IT-specialties. Sources: SCS [2], SSAC

Problem statement. Developing a heuristic method for quantitative assessment of ITspecialists' supply market.

Solution of the problem. The essence of the method is the development of a technique (heuristic algorithm) for obtaining information, which, together with the initial data, will enable the quantitative assessment of IT specialists' supply market. The algorithm assumes a consistent implementation of the following steps:

Step 1. To determine the dynamics of the number of IT specialists as the main indicator characterizing the IT-staff supply of the IT-profile education system. 
Step 2. To identify the key indicators shaping the output flow of IT specialists' supply, and to highlight those that are more stable, numerous and informationally supported.

Stage 3. To calculate the indicators shaping the need for the mandatory replacement of IT staff who left the industry.

Step 4. To analyze the supply and demand ratio for IT-professionals and assess the level of imbalance between them.

\section{Realization of the method of quantitative assessment of the supply market of IT specialists in Azerbaijan}

Step 1. The determination of the dynamics of the number of IT- specialists' as the main indicator characterizing the IT-staff's supply of the IT-profile education system.

As noted above, statistical information on the graduation of IT professionals is not available for today, however, there are data on their admission. As the information on the indicator "Graduation of IT-professionals", we decided to use the data on the admission of IT-professionals. The technique of acquiring the necessary information involves the assumption that the students admitted to the university in the academic year $t$ will become graduates after $(\mathrm{t}+4)$ years with a certain - out rate. To calculate the scale of dropout based on SSC's data, the graduation of students in year $t$ and their admission in a year $(t-4)$, that is four years ago, are comparatively analyzed, according to the formula:

$$
\delta(t)=\frac{N(t-4)_{\text {admission }}-N(t)_{\text {graduation }}}{N(t-4)_{\text {admission }}} \times 100
$$

where $N(t)_{\text {graduation }}$ is the graduation of students per year $t ; N(t-4)_{\text {admission }}$-admission of students per year $(t-4), 2008 \leq t \leq 2015$, the dropout rate is calculated, which is $3-5 \%$ per year. Taking into account the dropout rate, the approximate number of graduates in the IT group is calculated, the results of which are presented in Table 1.

Table 1

Dynamics of the total number of graduates of bachelor's course and the graduates of higher education institutions on the group of IT specialties (2008-2015).

Source: SSC [2], SSAC, authors' calculations

\begin{tabular}{|l|c|c|c|c|c|c|c|c|}
\hline & 2008 & 2009 & 2010 & 2011 & 2012 & 2013 & 2014 & 2015 \\
\hline $\begin{array}{l}\text { bachelor's graduates - } \\
\text { total, people }\end{array}$ & 29764 & 32005 & 28289 & 27438 & 31528 & 30368 & 28917 & 28985 \\
\hline $\begin{array}{l}\text { Including IT-specialists } \\
\text { (people) }\end{array}$ & 929 & 1164 & 1117 & 1354 & 1426 & 1712 & 2068 & 2094 \\
\hline $\begin{array}{l}\text { IT-specialists (\%) } \\
\text { (1) }\end{array}$ & 3,1 & 3,7 & 3,8 & 4,9 & 4,5 & 5,6 & 7,1 & 7,2 \\
\hline
\end{tabular}

As seen from Table 1, the share of IT specialists out of the total number of bachelor's graduates of in 2008 was $3.1 \%$, while in 2015, this figure increased more than 2 times.

The number of graduates in IT-specialties in a specific academic year is the current supply of IT specialists in the same year. Figure 5 illustrates the combined dynamics of the admission of students and the graduation of specialists (supply) on the group of IT specialties during 2007-2015. Figure 5 reflects the steady growth in the admission and graduation of IT specialists. 


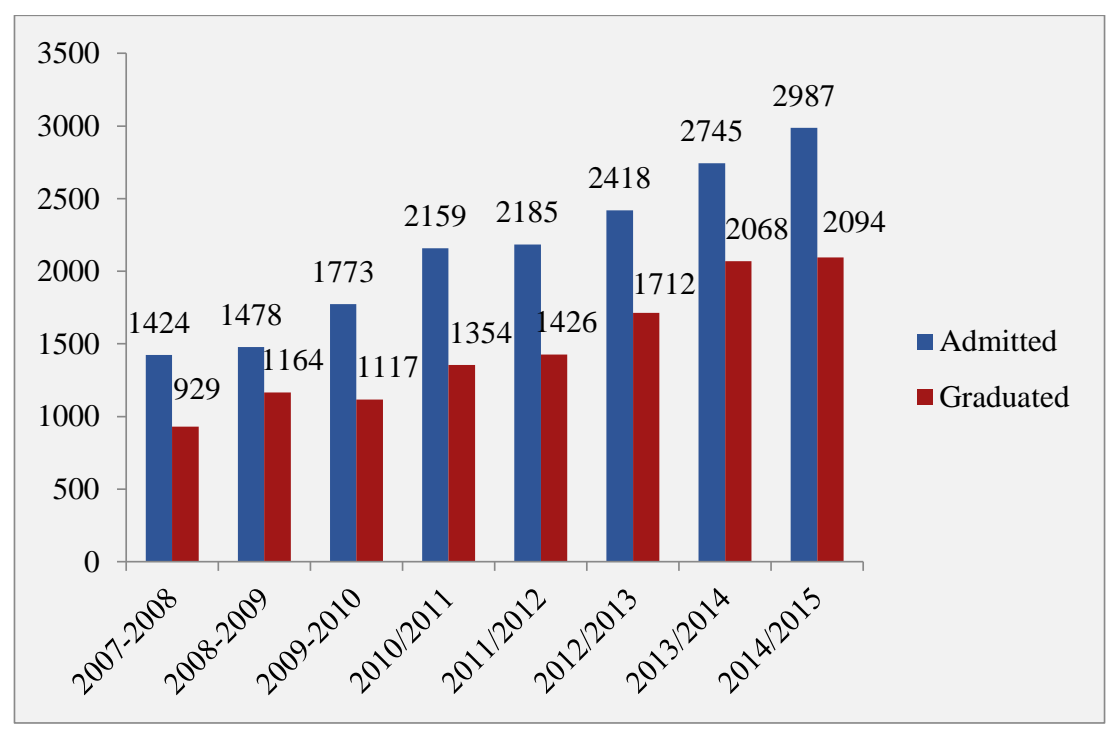

Fig.5. Dynamics of admission of students and graduation of specialists on the group of IT specialties. Sources: SSAC, authors' calculations

One of the important indicators characterizing the supply market of IT-specialists is the structure of students' admission to universities specialized in the field of IT in the context of professions and specializations. Table 2 demonstrates the quantitative distribution of the students' admission plan in IT-specializations for the period 2009-2014.

Table 2

Distribution of the students' admission in IT-specializations (2009-2014). Source: SSAC

\begin{tabular}{|l|c|c|c|c|c|c|}
\hline Years & $2009 / 2010$ & $2010 / 2011$ & $2011 / 2012$ & $2012 / 2013$ & $2013 / 2014$ & $2009-2014$ \\
\hline $\begin{array}{l}\text { Teaching Math and } \\
\text { Informatics }\end{array}$ & 611 & 644 & 636 & 729 & 818 & 3448 \\
\hline Computer Science & 349 & 434 & 478 & 588 & 584 & 2433 \\
\hline $\begin{array}{l}\text { Computer } \\
\text { Engineering }\end{array}$ & 240 & 314 & 468 & 361 & 441 & 1824 \\
\hline $\begin{array}{l}\text { IT and systems } \\
\text { Engineering }\end{array}$ & 393 & 545 & 508 & 518 & 627 & 2591 \\
\hline $\begin{array}{l}\text { Information } \\
\text { security }\end{array}$ & 0 & 0 & 0 & 0 & 15 & 15 \\
\hline Total: & 1773 & 2159 & 2185 & 2418 & 2745 & \\
\hline
\end{tabular}

Analysis of the distribution of the total number of admission on IT-specialization shows that for 5 years (2009-2014), admission to the IT specialty averagely accounted for 2062 students. Out of them, 33.4\% refers to the specialty "Teaching Mathematics and Informatics" accounting for 690 students per year; $25.2 \%$ - to the specialty "Information technology and systems engineering"; 23.6\% - Computer Science; 17.7\% - Computer Engineering; and 0,1\% - "Information security" (Fig. 6). The fact that $1 / 3$ of the admission plan of the group of IT specialties refers to "Teaching Mathematics and Informatics" can be explained by the important role of computer science teacher in the training of the younger generation in the life conditions in the information society, where information, scientific knowledge and innovation will play the decisive role. At the same time, the rest of IT-specialties account for $66.6 \%$ of the admission plan with average 1372 students per year for 5 years of the survey interval. 


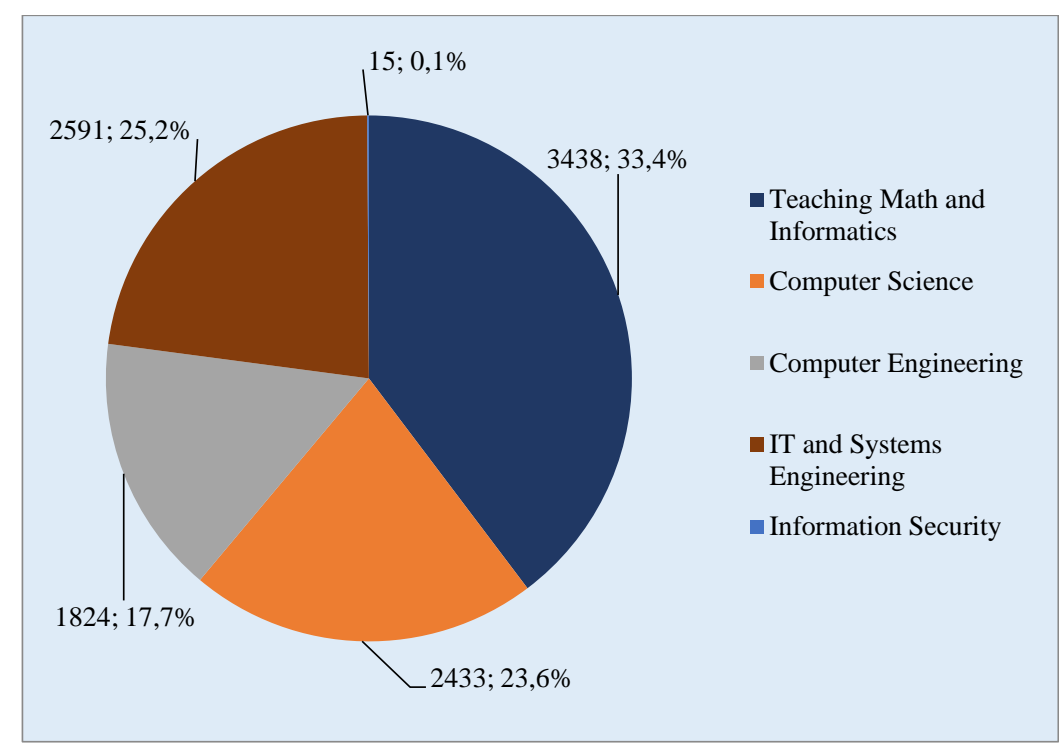

Fig.6. Distribution of the students' admission by the specializations. Source: SSAC

From our point of view, the existing planning system and the structure of admission are scientifically unjustified and do not represent the real situation in the sphere of quantitative correlation of supply and demand for IT specialists. The author's approach to the assessment of supply and demand ratio in the IT-segment of the labor market of Azerbaijan proposed in the work will enable confirming (or controverting) this assumption.

Stage 2. Identification of the main indicators shaping the output flow of IT specialists' supply, and the definition of those that are the most numerous and informationally supported, i.e. predictable.

To date, it is rather difficult to answer the question - how the real dynamics of the number of admission and the corresponding graduation of IT specialists satisfy the labor market demand, since the total supply of the latter is shaped from different sources [3-8]. In [8], a classification scheme of indicators defining the total supply of IT specialists is proposed, according to which the supply is formed through the interaction of in-and-out flows. The main sources of the incoming supply stream are the IT-profile graduates, working IT specialists, job seekers for one reason or another, unemployed IT specialists, etc. The outgoing stream is generated due to the categories, who left purely due to age reasons (retirement, including disability, mortality), changed their professional activities, temporarily left the labor market (illness, child care, military service, family circumstances), and emigration. In fact, the outgoing flow of supply is one of the sources of the current demand for IT-personnel in the economic sectors, and together with the demand for expanding IT-related industries, it forms the annual need for IT-specialists in the national economy. To determine the "real" supply of demand, the total number of the categories of ITspecialists accounting for the outgoing flow should be subtracted from the number of incoming flow of supply of the latter. In this case, two problems arise.

The first problem is the complexity of identifying the number of IT-specialists in practice shaping the outgoing flow due to the abovementioned categories. According to the international experience $[9,10]$, due to the difficulty of identifying the number of indicators, the outflow of supply (temporary exit from the labor market, emigration) is neglected assuming their insignificant numbers, or they are calculated by expert review. To identify other indicators of outflow of supply, including changing the professional activity, the further activities of IT-specialists are monitored or the sociological surveys of former graduates are conducted, based on certain methodologies [5, $11,12]$.

The second problem is related to the need for the management of the processes of professionals' exit from the IT sphere and their timely replacement. In order to make the 
replacement process more manageable, it is necessary to select the category of IT specialists, which is the most numerous and informationally supported, out of the set of indicators shaping the outgoing flow. According to the practice of the specialized agencies, such as the International Civil Aviation Organization, the International Telecommunication Union, the United Nations, the World Health Organization, and others, the work on retirees accounting is the priority of staff replacement planning. At the same time, announcements of relevant (potential) vacancies are published before retirement. Administrative offices and member states have online access to a five-year forecast of retirement of employees of different categories and levels [13]. Consequently, the category of retiring IT-specialists can be referred as the required indicator.

Stage 3. Calculation of the indicators shaping the need for the mandatory replacement of ITstuff who left the economy.

In the context of the foregoing, an approach is proposed for the assessment of the supplydemand ratio in the IT-segment of the labor market. The essence of the approach is reduced to the calculation of the indicator "retired IT-specialists" and to the joint analysis of: the dynamics of the number of employed IT specialists both in the IT sector and in the national economy; retired ITspecialists both in the IT sector and in the national economy; inflow (number) of graduates in ITprofile specialties.

For the calculation of the indicator "Retired IT-specialists", the average of the work period is assumed 39 years. The average duration of the work period is calculated based on the retirement age specified in Azerbaijan until 2016 (for men at the age of 63, for women - 60) and on the average age of graduation of the bachelor's program (approximately at the aged of 22). Given these data, the retirement coefficient per year is calculated to be $k_{R}=0,026$ (1/39). Further, according to formulas (2) and (3), the number of IT-specialists retired in the ICT sector and in the context of the types of economic activities (TEA) is determined:

$$
\begin{gathered}
P(t)_{I C T}^{R}=k_{R} \cdot P(t)_{I C T} \\
P(t)_{T E A}^{R}=k_{R} \cdot \sum_{i=1}^{m-1} P^{i}(t),
\end{gathered}
$$

where $i=\overline{1, m-1} ; m=18$ is the number of TEA, $P(t)_{I C T}$ - the total number of IT-specialists employed in the ICT sector, $\sum_{i=1}^{m-1} P^{i}(t)$ - the total number of IT-specialists employed in other sectors of the economy of Azerbaijan, $k_{R}$ - the retirement coefficient per year.

Table 3 and figure 7 display the statistical and calculated indicators (the number of ITspecialists employed in the ICT sector and sectors of the economy, the number of IT graduates, the number of retired IT specialists) directly involved in the identification of the need for replacement and a real supply of IT professionals.

Table 3

Statistical and calculated indicators specifying the need for replacement of IT-specialists and its coverage (2011-2015). Source: * SSC; ** authors' calculations [14].

\begin{tabular}{|l|c|c|c|c|c|}
\hline Indicators & 2011 & 2012 & 2013 & 2014 & 2015 \\
\hline $\begin{array}{l}\text { IT-specialists employed in the ICT sector *- } \\
P(t)_{\text {ICT }}\end{array}$ & 18300 & 18500 & 19300 & 19900 & 20100 \\
\hline $\begin{array}{l}\text { IT-specialists employed in other sectors of the } \\
\text { national economy } * *-\sum_{i=1}^{m-1} P^{i}(t)\end{array}$ & 28374 & 31092 & 33602 & 34995 & 35871 \\
\hline IT-specialists retired in the ICT sector $P(t)_{\text {ICT }}^{R}$ & 476 & 481 & 501 & 517 & 523 \\
\hline
\end{tabular}




\begin{tabular}{|l|c|c|c|c|c|}
\hline $\begin{array}{l}\text { IT-specialists retired in other sectors of the } \\
\text { national economy }-P(t)_{\text {TEA }}^{R}\end{array}$ & 737 & 808 & 838 & 910 & 933 \\
\hline Total number of retired IT-specialists $-P(t)^{R}$ & 1213 & 1289 & 1339 & 1427 & 1456 \\
\hline Number of IT graduates $-N(t)_{\text {graduatior }}$ & 1354 & 1426 & 1712 & 2068 & 2094 \\
\hline
\end{tabular}

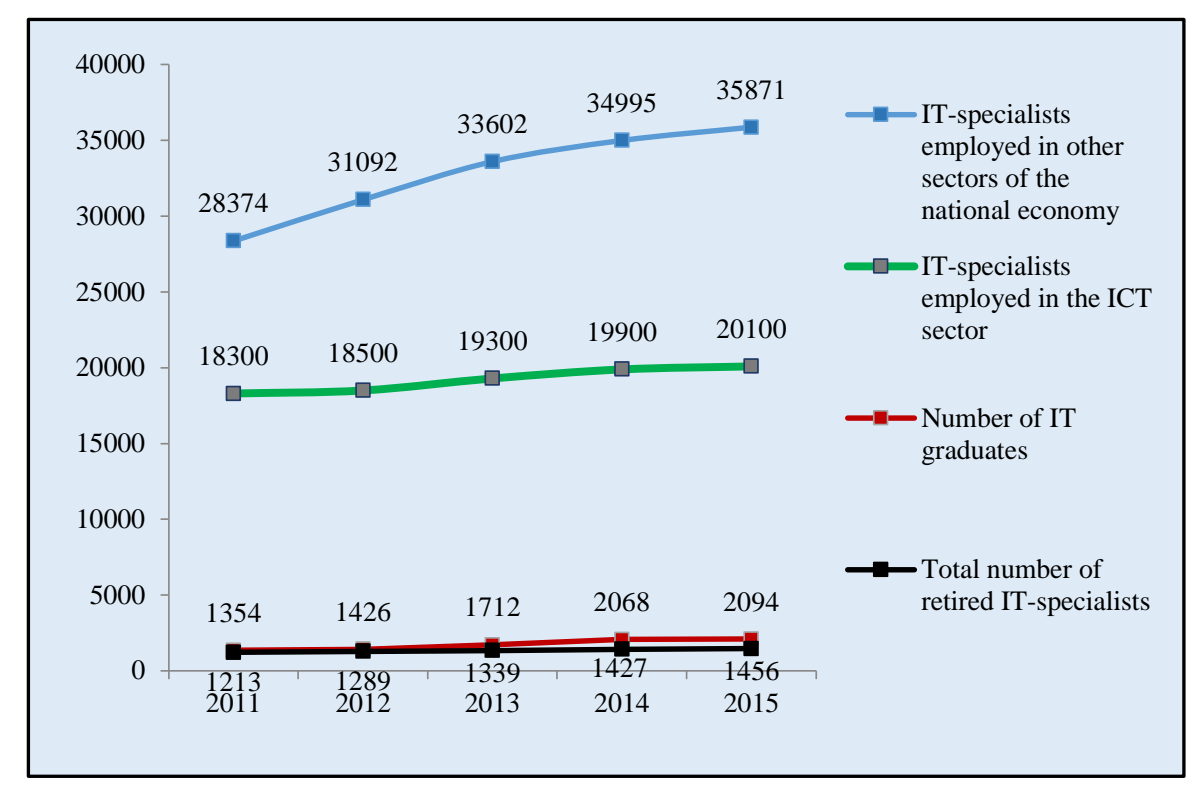

Fig.7. Dynamics of the indicators specifying the need for replacement of IT-specialists and its coverage. Sources: GCS, estimated data

Stage 4. Analysis of the supply-demand ratio for IT-specialists.

Table 4 reflects the dynamics of: 1) demand and supply for IT-specialists; 2) the number of IT-specialists required to cover the replacement; 3) the real supply (inflow) of IT-specialists after covering the replacement.

Comparative analysis of targeted indicators, based on their retrospective data, identifies the current state of the labor market of IT-specialists, i.e. determines the ratio of supply and demand in the IT segment of the labor market. Thus, calculations show that the total number of retired ITspecialists accounts for 6724 people for 5 years or averagely 1344.8 people per year, whereas the number of IT-profile graduates comprises 8,654 IT specialists for 5 years or averagely $1,730.8$ people per year. The study of the dynamics of the number of IT-specialists (demand) in Azerbaijan for the period 2011-2015 identifies the growth of IT-specialists in the ICT sector (Table 4 (III)), which accounts for 1800 people for 4 years, i.e., 450 IT specialists per year in the ICT sector, while this figure accounted for 7497 people for 4 years or averagely 1,874 people per year in other fields of the national economy (Table 4 (IV)). Thus, the real supply of IT specialists (graduates) after covering the replacement of retired ones averagely accounts for 386 people (Table 4 (II, III, VI)).

Further, the total demand (need) in IT specialists (Table $4(\mathrm{~V})$ ) averaged 2324 people per year. This means that the average supply-demand ratio for IT-specialists is 1:6 (2324/386). At the same time, in the ICT sector this ratio is 1:1.17 (450/386), i.e., the demand and supply in this sector are assumed to be quantitatively balanced. However, in the sectors of the national economy, the supply-demand ratio is 1: 4.85 (1875/386), i.e., there is a significant imbalance between these indicators. 
Dynamics of the supply-demand ratio for IT-specialists for the period 2011-2015.

\begin{tabular}{|c|c|c|c|c|c|c|}
\hline Years & $\begin{array}{c}\text { Supply of } \\
\text { IT- } \\
\text { specialists } \\
\text { (number of } \\
\text { graduates) }\end{array}$ & $\begin{array}{c}\text { Growth of } \\
\text { employed IT- } \\
\text { specialists in the } \\
\text { ICT sector } \\
\text { (demand) }\end{array}$ & $\begin{array}{c}\text { Growth of } \\
\text { employed IT- } \\
\text { specialists in } \\
\text { other sectors of } \\
\text { economy } \\
\text { (demand) }\end{array}$ & $\begin{array}{c}\text { Total } \\
\text { growth of } \\
\text { employed } \\
\text { IT-spec.in } \\
\text { all sec. of } \\
\text { ec. } \\
\text { (demand) }\end{array}$ & $\begin{array}{c}\text { Number of } \\
\text { IT- } \\
\text { specialists } \\
\text { needed for } \\
\text { the } \\
\text { replacement } \\
\text { (demand) }\end{array}$ & $\begin{array}{c}\text { Real } \\
\text { supply of } \\
\text { IT-spec. } \\
\text { after } \\
\text { replaceme } \\
\text { nt }\end{array}$ \\
\hline I & II & III & IV & V & VI & VII \\
\hline 2011 & $13)_{\text {graduatior }}$ & $\Delta\left(P(t)_{I C T}\right)$ & $\Delta\left(\sum_{i=1}^{m-1} P^{i}(t)\right)$ & $\Delta\left(P(t)_{T E A}\right)$ & $P(t)^{R}$ & $N(t)_{\text {real }}$ \\
\hline 2012 & 1426 & 200 & 2718 & 2918 & 1289 & 137 \\
\hline 2013 & 1712 & 800 & 2510 & 3310 & 1339 & 373 \\
\hline 2014 & 2068 & 600 & 1393 & 1993 & 1427 & 641 \\
\hline 2015 & 2094 & 200 & 876 & 1076 & 1456 & 638 \\
\hline Total & 8654 & 1800 & 7497 & 9297 & 6724 & 1930 \\
\hline av./ year & 1730,8 & 450 & 1874.2 & 2324,2 & 1344,8 & 386 \\
\hline
\end{tabular}

The calculated data on the supply-demand ratio in the IT segment of the labor market comply with the results of the monitoring of demand and supply for IT professionals [5, 15]. A comparative analysis of the latter allows us to make a conclusion regarding the compensation of the deficit of IT specialists due to a steady inflow of the two leading specialists' categories into the IT segment of the labor market, who have:

1) IT-related education (physical and mathematical, engineering and technological);2) basic education in the specialties completely unrelated to information technology (biologist, lawyer, journalist, economist, architect, chemist, etc.). When assessing the imbalance between supply and demand for IT specialists, one more important result obtained by the feedback of former IT-profile graduates should be taken into account. This is the identification of the indicators, such as the share of IT specialists who have changed the field of activity, and the share of IT graduates who are not included into the labor market $[1,5]$.

The current situation in the IT segment of the labor market in Azerbaijan, particularly related to the quantitative mismatch of supply and demand for IT specialists, reveals a significant inconsistency between the plan for admission of students to the IT profession and the real situation in the labor market. Another reason for this situation is the structural and qualitative (skill) indicators of the inconsistency between the IT training system and the needs of the labor market $[5,15]$. It should also be noted that the career duration of IT specialists /practitioners ends relatively early (at the age of 40-50) [16, 17].

\section{Conclusion}

The determination of the imbalance of supply and demand for IT-specialists based on the proposed heuristic method of quantitative assessment of the IT-supply market allowed us to conclude that the shortage of IT specialists stems from the informatization of the national economy. Taking into account the trends of the state policy in the field of ICT development in Azerbaijan for the further informatization of economic sectors and the establishment of an information society in the country, a significant increase in the demand for IT specialists is predicted. This means that the problem of IT-workforce supply becomes particularly important not only within the IT industry, but also at a macroeconomic scale. Of course, the frameworks on 
the development of ICT in the Republic of Azerbaijan focus on the formation of appropriate human resources. The training of IT workforce at various levels of education is linked to the development goals of the ICT sphere and to the needs of the national economy.

The proposed technique for analyzing IT-profile education and the compliance of supply and demand of IT specialists in Azerbaijan can be a basis for the management decision support on the compliance of the latter and on the forecasting a plan for the students' admission to IT specialties in accordance with the prospects for innovative development of the country.

\section{References}

1. Strategic Roadmap for Telecommunications and Information Technology Development, December 6, 2016, p. 65, http://www.president.az/articles/22382

2. Education, science and culture in Azerbaijan, Statistical bulletin, http://www.stat.gov.az.

3. McGuinness S., Pouliakas K., Redmond P. How useful is the concept of skills mismatch? ILO, Geneva, 2017, 44 p.

4. Measuring skills mismatch. Analytical Web Note. European Commission. Luxembourg: Publications Office of the European Union, 2015, 44 p.

5. Mammadova M.H., Jabrailova Z.G., Mammadzada F.R. Demand and Supply in the ITsegment of the Labor Market of Azerbaijan // Problems of information technology, 2016, №2, pp.107-122.

6. Mammadova M.H., Jabrayilova Z.G., Mammadzada F.R. Fuzzy approach to estimate the demand and supply quantitative imbalance at the labor market of information technology specialists // International journal of Intelligent Systems and Applications in Engineering, 2015, vol.3, no.4, pp.140-143.

7. Mammadova M.H., Mammadzada F.R Object-oriented approach to determining the relevance of IT education to the demand in the market of IT-specialists // Education and Science, Moscow, 2014, No 5, pp.54-67.

8. Mammadova M.H., Mammadzada F.R Development of the conceptual basics for the intellegent management of the demand and supply of IT-specialists in the labor market // EastEuropean Journal of Advanced Technologies, 2015, Vol. 4, No 3 (76), pp.53-67.

9. Didero M., HusingT., Korte W.B. Monitoring e-Skills demand and supply in Europe: Synthesis report "The evolution of the supply and demand of e-Skills in Europe". European Commission, 2009, 58 p.

10. Ticol D. Labour supply/demand dynamics of Canada's information and communications technology (ICT) sector. Final Report /Nordicity, 2012, 30 p.

11. http://www.skillsireland.ie/Publications

12. https://www.maastrichtuniversity.nl/research/research-centre-education-and-labour-market

13. Sukeyri R.M. Planning the replacement of staff in the organizations of the UN system, Geneva, 2016, p.115.

14. Masuma H. Mammadova, Faig R. Mammadzada. Development of the technique of assessing the total number of it professionals in Azerbaijan // Problems of information technology, 2018, №1, pp.53-64

15. Mammadova M.H., Jabrayilova Z.G., Manafli M.I. Monitoring of demand for IT-specialists, Baku: "Information Technology", 2009, 199 p.

16. Stetsenko A. Age discrimination in IT and how to live with it, https://dou.ua/lenta/columns/age-in-it

17. Sutcliffe J. Four common tech ageism myths debunked with data, 2017, https://www.visier.com/clarity/four-common-tech-ageism-myths-debunked 